\title{
The Effect of Clil Method on Teaching Reading Comprehension to Junior High School Students
}

\author{
Nadia HAMIDAVI ${ }^{1, *}$, Mansoureh Shekar AMIZ ${ }^{2}$, Bahman GoRJIAN ${ }^{3}$ \\ ${ }^{1}$ Department of ELT, Ahvaz Branch, Islamic Azad University, Ahvaz, Iran \\ Email: nadiahamidavi2@gmail.com \\ ${ }^{2}$ Assistant Professor, Department of ELT, Ahvaz Branch, Islamic Azad University, Ahvaz, Iran \\ Email: mansoore.shekaramiz@gmail.com \\ ${ }^{3}$ Associate Professor, Department of ELT, Abadan Branch, Islamic Azad University, Abadan, Iran \\ Email: bgbahgorji@yahoo.com
}

\begin{abstract}
This study investigated the effect of CLIL (i.e., content and language integrated learning) on Iranian EFL learners' reading comprehension. 60 students of junior high school in the age of 12 to 14 years who attended language institutions were selected non-randomly. They took part in Oxford Quick Placement Test (OQPT) test to determine their level of proficiency. Based on their scores in the placement test, the students were divided into two groups: High and low achievers. Then they took a pre-test of reading comprehension. Depending on their scores in the pretest, the high level and the low level groups were divided into two subgroups of experimental and control. The experimental groups of high and low achievers were taught through CLIL and the control groups of high and low achievers were taught through intensive reading. After ten sessions of treatment, they took a post-test of reading comprehension. Data were analyzed to compare the high and low achievers with each other to examine the effectiveness of CLIL method through Independent Samples t-test. The findings showed a significant difference between the pre and post-test of high and low achievers. Implications of CLIL method could be influential for both high and low achievers in reading comprehension courses.
\end{abstract}

Keywords: CLIL, foreign language, EFL, reading skills, high school learners

\section{Introduction}

Content and language integrated learning (CLIL) has been initiated in Europe since 1994. According to Mehisto (2012), this term was launched during 1994 in conjunction with the European Commission. Ortiz (2014) stated that it was defined and launched by UNICOM, University of Jyväskylä and the European Platform for Dutch Education in 1994. Dissatisfied with the outcomes of grammar-focused language teaching and inspired by theories about natural language learning, an alternative method for language teaching was created in the 1960s (Brinton, Snow \& Wesche, 1989). This new method of language teaching tries to further language development by eliminating the artificial separation between language instruction and subject matter classes. In other words, a dual-focused educational approach in which an additional language is used for the learning and teaching of both content and language could be developed (Mehisto, Marsh \& Frigols, 2008).

According to Solé (1998), reading is a process of interaction between the writer and the reader on a text to get the meaning. The interaction involves two types of knowledge: a previous one 
established by the knowledge of the linguistic nature; and the schematic one, referring to partial knowledge, structured, that we have in the memory about issues, situations, typical events of our culture. Thus, the meaning is not in the text, which is barely the vehicle of communication between author and reader, but it is suggested by the author and built by the reader. Reading is searching for a meaning, and the reader should have a purpose to find the meaning in the text. You read with a purpose when it has a meaning. The interpretation that the readers made of the text depends mainly on the object that the reading has.

It is possible that two or more readers, motivated by different goals or by a different layout or different information extract from the same text. It can be stated that reading is an experience in which the whole personality of the reader gets into interaction with the text because only the reader develops and extracts the significant potential of it. According to Zurek (2012), to teach language skills especially reading more effectively, CLIL are one of the best methods that has been taught in Europe for many years. CLIL stands for "Content Language Integrated Learning" and its other names are "content- based learning" and "cross- curricular content" (Aldaz, 2013). It is a method that integrates both Content Learning and Language Learning and is the advancement of CLT (communicative language teaching). According to Coyle, Hood and Marsh (2010), CLIL is a dualfocused educational approach in which additional language is used for the learning and teaching of both content and language. In CLIL a foreign language is used as a channel in the learning of a subject in which both language and subject have an interaction (Marsh, 2002).

The main objective of this study is to analyze the impact on learners' reading skills involved in a CLIL project and find out if there is a significant advantage over those students at the same grade who are not involved in a CLIL program. Therefore, I formulated the following question: RQ. Do the students who are taught reading comprehension through CLIL, learn and perform better than those who are taught through intensive reading?

\section{Literature Review}

Content and Language Integrated Learning (CLIL) is a new pedagogical model for second language education, developed in Europe in the mid-1990s. To refer to this kind of teaching, the acronym CLIL (content and language integrated learning) has been coined to function as an umbrella term for the numerous expressions used in different countries and educational settings (Dalton-Puffer \& Smit, 2007). The acronym itself was defined by David Marsh in 1994 and explained as follows: "CLIL refers to situations where subjects, or parts of subjects, are taught through a foreign language with dual-focused aims, namely the learning of content and the simultaneous learning of a foreign language" (Marsh, 2002). This means that, in the teaching and learning process, there are two objectives, one linked to learning the particular subject matter (such as science, history or geography), and the other related to the foreign language, which becomes the means for learning content. "achieving this two-fold aim calls for the development of a special approach to teaching in that the non-language subject is not taught in a foreign language but with and through a foreign language.

Even though the term "CLIL" was coined in 1994, the practice of it has been around for a long time with its roots in immersion education from the 1970s and 1980s. Coyle (2007, 2010) points out CLIL are not a form of language education or subject education; it is an innovative fusion of both. CLIL is an educational approach which responds to the contextual needs. CLIL in many contexts is considered to be a solution to the limited number of hours of the foreign language instruction in the curriculum. Integrating content and language increases the number of contact hours with the language and provides more exposure to the foreign language which is one of the necessary catalysts for Language acquisition to occur (Merikivi \& Päivi, 2014). 
Coyle (1999) developed the 4Cs model to support CLIL pedagogy and in 2006 he mentioned that an effective CLIL lesson combines elements of content (subject matter), communication (language), cognition (thinking) and culture (awareness of self and 'otherness'). Content refers to the progression in knowledge, skills and understanding that students do related to specific elements of a defined curriculum. Communication is about using language to learn while learning to use the language. Cognition refers to thinking skills which link concept formation (abstract and concrete), understanding and language. Finally, culture refers to the exposure to alternative perspectives and shared understandings, which deepen awareness of others and self. Coyle (2006) considered that 'for CLIL to be effective all 4Cs must be carefully considered in the planning and conceptualization stages of the teaching as well as the monitoring and evaluation of the learning.

Appropriate teaching and learning strategies had not been agreed upon, but were developed by trial and error. Instructors began by focusing on helping learners to understand the L2 (French) and to develop oral communication skills. A more balanced approach that included all four language skills (i.e. listening, speaking, reading and writing) was introduced once the students' aural and oral skills had developed sufficiently to allow for basic communication. In general, the program was highly successful, which is why the use of immersion teaching began to spread thorough Canada during the 1970s and the 1980s, and involved other languages (e.g. English for French-speaking children). Furthermore, studies on students in Canadian French immersion programs suggested that they are highly motivated and also have a very positive attitude towards French. Pupils who only have regular instruction in French often complain about having too many French lessons. Most of the immersion pupils, on the other hand, say that they like being taught through French and that they want to continue to learn French after school (Cummins \& Swain, 1996).

Swain and Lapkin (1995) encouraged immersion pupils who were working in pairs to verbalize their thoughts while completing writing and editing tasks. An analysis of the pupils' talk showed that they were engaged in several reasoning processes such as judging the grammaticality of their production, trying to apply rules, searching for alternatives and assessing these. Based on this and similar studies Swain (1995) concluded that comprehensible output has three important cognitive functions to fulfill, which apparently could not be realized in the input- focused immersion classrooms. These functions are:

- Noticing

- Hypothesis testing

- Conscious reflection on language structure

Following Krashen's (1985) ideas, CLIL students seem to be less inhibited when it comes to using the foreign language. Dalton-Puffer (2008), in her study on discourse in Austrian CLIL classrooms, could observe that pupils do not seem embarrassed if they lack vocabulary knowledge. Rather, they acknowledge their lexical gaps and initiate repair. This is very different from behavior which can be observed in regular language lessons. Dalton - Puffer found out that under CLIL conditions certain aspects of language competence were developed more than others. Areas affected by CLIL were: receptive skills, vocabulary, morphology, creativity, risk-taking, fluency, quantity and Emotive/affective outcomes. Areas that were not affected by CLIL were: Syntax, Writing, Informal/non-technical language, Pronunciation, and Pragmatics (Munoz, 2014).

Gefall's (2009) studies on CLIL showed that the students' lack of grammatical knowledge was related to restrictions in input and limited opportunities for interaction and producing output in CLIL classrooms. In other words, certain grammatical structures such as conditional sentences and past tense were absent in classroom instruction and therefore could not be acquired. Moreover, Swain (1995) in her output hypothesis argued about the problems of CLIL students in developing a high grammatical competence in the target language. Since processes which seem to be encouraged 
most in comprehensible reflection, are underused in input-focused CLIL classrooms. Interpreting these results by applying constructivist's concepts revealed that opportunities for constructing grammatical knowledge in the target language are limited in the CLIL classroom. In addition, meaning-focused CLIL classrooms do not seem to cause enough disequilibrium in the pupils when it comes to developing grammar competence in the foreign language.

To teach subjects like history, physics, and chemistry, Divljan (2012) observed that female students showed more progress in learning languages while male students were more successful at learning natural sciences. After teaching through CLIL male students became more fluent in the target language and female students showed more progress in physics and chemistry. Therefore, based on his studies and researches, Divljan concluded that using various instructional approaches that can integrate content- and language-learning objectives and applying whole language strategies in a foreign language classroom can definitely facilitate the learning and teaching processes.

\section{Method}

\subsection{Participants}

To carry out the study, the researcher selected a sample of 80 junior high school pupils within an age range between 12 and 14. This age level was selected since in this age learners are very enthusiastic to learn experience and discover to satisfy their curiosity. All of them were female. Their information about English was what they had learned at school or language institutions. The learners took OQPT to determine their level of proficiency. Thus, 60 learners who took 0 to 36 out of 60 were selected as the participants of the study. The learners who got the band score of 0 to 18 were assigned as elementary (i.e., henceforth, low achievers) and the learners who got 19 to 36 were assigned as the pre-intermediate level (i.e., henceforth, high achievers). Then each group was divided non-randomly in two sub-group of experimental and control groups, each included 15 participants. The experimental groups were taught through CLIL method and the control groups received traditional reading comprehension courses.

\subsection{Instrumentation}

To accomplish the objective of the present study, the following instruments were employed: A placement test: The placement test was OQPT which was used based on which students were homogenized. The students who took scores from 0 to 36 out of 60 were classified into two band scores of elementary and pre-intermediate level of language proficiency. Since OQPT is a standard test, its reliability and validity were reported in some articles.

A pretest was designed based on the participants' text book "Foreman's Science Book Series" (Foresman, 2006) for the high achievers and "Select Readings: Elementary (Lee, 2011) for low achievers in the experimental and control groups. The pre-tests were reading based and they included 50 multiple-choice items designed based on 12 reading passages in the text-books. The test was taken to evaluate student's ability in revealing their knowledge and enabling the teacher to know the students' reading comprehension scores in the beginning of the course. The reliability of the test was calculated based on KR-21 method as ( $\mathrm{r}=.864)$.

A post-test for high and low achievers included 50 multiple-choice items and they were as the same as the pre-test with some modification in format in order to avoid the participants' reminding. They were used to evaluate the effectiveness of the CLIL method on learners' reading improvement in both control and experimental groups at the end of the treatment. Its reliability was met through a pilot test regarding the KR-21 formula as $(\mathrm{r}=.749)$. 


\subsection{Materials}

The materials included reading passages selected from "Foresman's Science Book Series" (Foresman, 2006) for high achievers and "Select Readings: Elementary (Lee, 2011) for low achievers. For the low achievers in the control and experimental groups, reading passages were selected from "Select Readings: Elementary". For the high achievers in the control and experimental groups, the text book "Foresman's Science Book Series" were used based on the students' level.

\subsection{Procedure}

To accomplish the purpose of the study and to put CLIL method into practice four groups each consists of 15 students were selected. The placement test was Oxford Quick Placement Test (OQPT) which was used based on which students were homogenized. The students who took 36 out of 55 are classified into high achievers and those who took less than 35 are placed into the low achievers.

The pre-test was extracted from "ESL Photocopiable Activities" (pre-intermediate for high levels and beginner \& elementary for low levels) Cambridge University Press were used to enable the teacher to determine the appropriate texts for each group. Students who took above 70 out of 100 were placed in the control groups and those who got less than 30 were placed in the experimental groups. Then both groups were divided into four subgroups (i.e., high and low achievers in the control group and high and low achievers in the experimental group. Both control groups were taught through intensive reading courses. The text book was "Select Readings: Elementary". The experimental groups are taught through CLIL and the selected texts were chosen from "Foresman's Book Series". In each class reading was taught three times a week and each session lasted one hour. The classes were held 12 sessions: the first session was devoted to pre-test, 10 sessions were devoted to treatment, and the last session was devoted to post- test. Reading texts should be topicbased to make students expose to abundant comprehensible input of authentic language to facilitate language acquisition and language learning. After the treatment, the modified pre-test was used as a post-test which focused on the same content but different form to avoid the participants' reminding was designed as a reading comprehension exam.

\section{Data Analysis}

In order to determine whether CLIL program has any effect on learners' reading improvement, the pre-test and post-test scores were analyzed using Independent Samples t-test through SPSS version 17.

\section{Results}

Focusing on the effect of CLIL (content and Language Integrated Learning) on the improvement of learners' reading comprehension, the statistical calculations and results are presented and then the result of analysis of the null hypothesis will be discussed. Therefore, the results to reject or confirm the research hypotheses will be offered in the following section.

At the beginning of the study two groups were given a pre-test. After the pre-test, each level was divided into two groups as strong group and weak group. After a ten- session treatment in which strong groups were taught through intensive reading, a post test was taken and the obtained 
results of groups in high levels were compared through Independent Samples t-test. The descriptive statistics of pre-test and post-test in high levels are presented in Table 1.

Table 1.Descriptive Statistics (High achievers)

\begin{tabular}{l|llccc}
\hline \multicolumn{1}{l}{} & Groups & $\mathrm{N}$ & Mean & Std. Deviation & Std. Error Mean \\
\hline \multirow{2}{*}{ Pre-test } & Control & 15 & 40.4667 & 3.39888 & .87759 \\
& Experimental & 15 & 43.8000 & 15.31666 & 3.95474 \\
\hline \multirow{2}{*}{ Post-test } & Control & 15 & 65.6000 & 5.47462 & 1.41354 \\
& Experimental & 15 & 87.0667 & 15.13967 & 3.90905 \\
\hline
\end{tabular}

Table 1 shows that the average means for every two groups was near and the difference between two groups was not significant. To find out whether the difference among the performances of the two groups was statistically significant, an independent sample t-test was applied. Table 2 displays the results of the statistical operations.

Table 2. Independent Samples t-Test (High achievers)

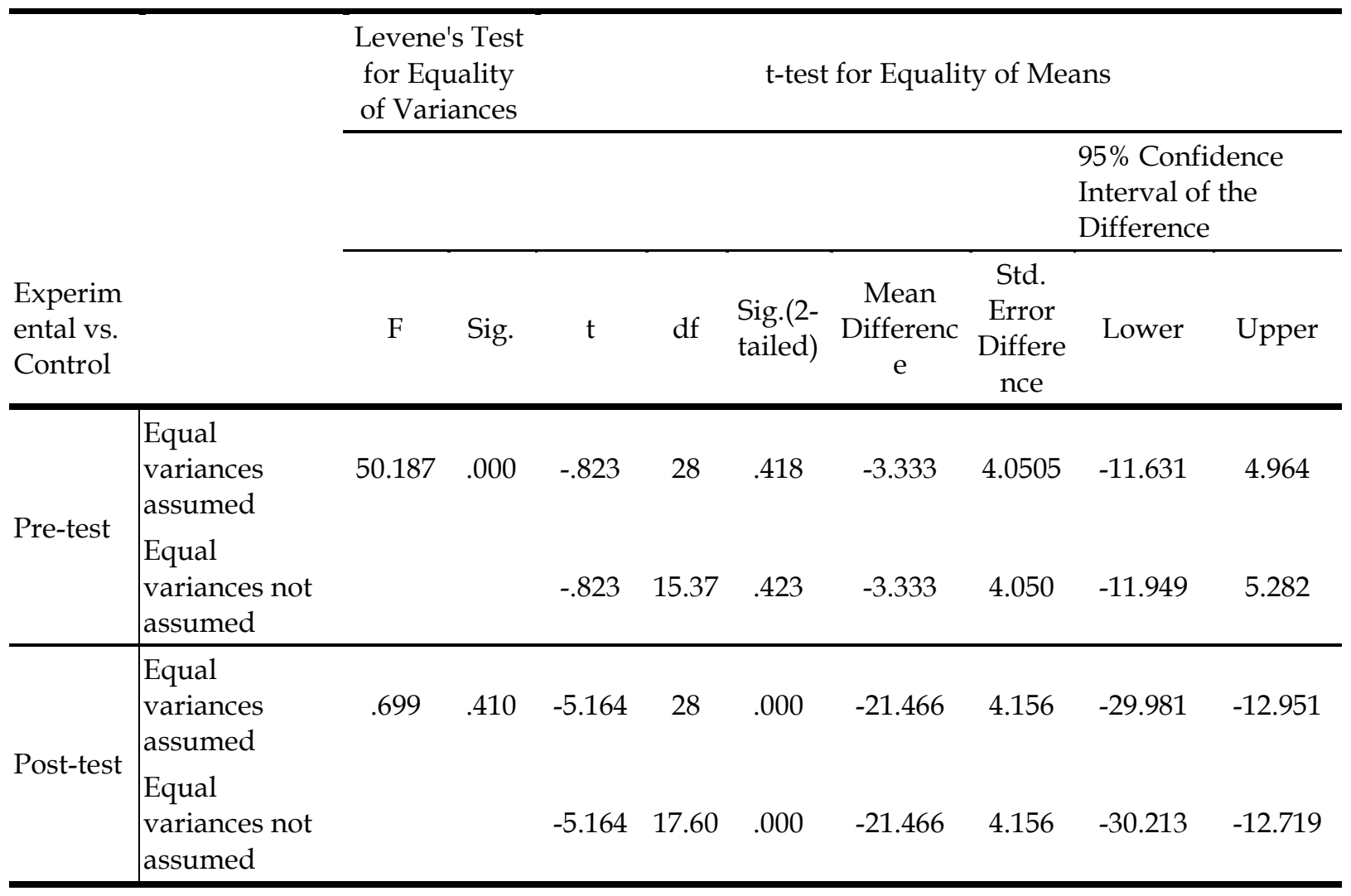

Table 2 shows that the observed $t(0.823)$ is less than the critical $t(1.701)$ with $\mathrm{df}=28$. Thus, the difference between the groups is not significant in the pre-test $(p<0.05)$. Since the observed $t$ (5.164) is greater than the critical $t$ (1.701) with $\mathrm{df}=28$, the difference between the groups is significant in the post-test $(\mathrm{p}<0.05)$. After a ten- session treatment in which weak groups were taught through CLIL, a post test was taken and the obtained results of groups in low levels were 
compared through Independent Samples t-test. The descriptive statistics of pre-test and post-test in low levels are presented in Table 3.

Table 3. Descriptive Statistics (Low achievers)

\begin{tabular}{|c|c|c|c|c|c|}
\hline & Groups & $\mathrm{N}$ & Mean & Std. Deviation & Std. Error Mean \\
\hline \multirow[t]{2}{*}{ Pre-test } & Control & 15 & 39.4667 & 10.76945 & 2.78066 \\
\hline & Experimental & 15 & 44.8000 & 11.29602 & 2.91662 \\
\hline \multirow[t]{2}{*}{ Post-test } & Control & 15 & 51.3333 & 3.39467 & .87650 \\
\hline & Experimental & 15 & 73.4667 & 13.03767 & 3.36631 \\
\hline
\end{tabular}

Table 3 indicates that the average means for every two groups is near and the difference between two groups is not significant. To find out whether the difference among the performances of the two groups was statistically significant, an Independent Samples t-test was applied. Table 4 displays the results of the statistical operations.

Table 4. Independent Samples t-test (Pre-test and Post-test)

\begin{tabular}{|c|c|c|c|c|c|c|c|c|c|}
\hline & \multicolumn{4}{|c|}{$\begin{array}{l}\text { Levene's Test } \\
\text { for Equality } \\
\text { of Variances }\end{array}$} & \multicolumn{5}{|c|}{ t-test for Equality of Means } \\
\hline & & & & & & & & \multicolumn{2}{|c|}{$\begin{array}{l}\text { 95\% Confidence } \\
\text { Interval of the } \\
\text { Difference }\end{array}$} \\
\hline & $\mathrm{F}$ & Sig. & $\mathrm{t}$ & $\mathrm{df}$ & $\begin{array}{l}\text { Sig. (2- } \\
\text { tailed) }\end{array}$ & $\begin{array}{c}\text { Mean } \\
\text { Difference }\end{array}$ & $\begin{array}{c}\text { Std. Error } \\
\text { Differenc } \\
\mathrm{e}\end{array}$ & Lower & Upper \\
\hline Equal variances assumed & .196 & .661 & -1.323 & 28 & .196 & -5.333 & 4.029 & -13.58 & 2.92 \\
\hline $\begin{array}{l}\text { Equal variances not } \\
\text { assumed }\end{array}$ & & & -1.323 & 27.93 & .196 & -5.333 & 4.029 & -13.58 & 2.92 \\
\hline Equal variances assumed & 1.773 & .194 & -6.363 & 28 & .000 & -22.133 & 3.478 & -29.25 & -15.00 \\
\hline $\begin{array}{l}\text { Equal variances not } \\
\text { assumed }\end{array}$ & & & -6.363 & 15.89 & .000 & -22.133 & 3.478 & -29.51 & -14.75 \\
\hline
\end{tabular}

Table 4 shows the observed $\mathrm{t}(1.323)$ is less than the critical $\mathrm{t}(1.701)$ with $\mathrm{df}=28$. Thus the difference between the groups is not significant in the pre-test. Since the observed t (6.363) is greater than the critical $\mathrm{t}(2.00)$ with $\mathrm{df}=28$, the difference between the groups is significant in the post-test.

\section{Discussion}


This section elaborates on the results and findings to answer the research question raised earlier in the study will be referred to as follows: Do the students who are taught reading comprehension through CLIL, learn and perform better than those who are taught through intensive reading courses?

Results of the study showed that the two experimental groups of high and low achievers could outperform their counterparts. However, high achievers performed better than the low achievers in the post-test of the experimental group. Thus CLIL method could enhance the learners' reading comprehension among both high and low achievers. The results of the present study are in line with some scholars (e.g., Lightbown \& Spada, 2006; Naves, 2010; Saville, 2006) who state that CLIL offers the required conditions for language acquisition to occur, it enables learners to use another language naturally, in such a way that they soon forget about the language and only focus on the learning topic. However, some researchers like stated that CLIL does not guarantee the success in language acquisition unless several important aspects are fulfilled. They identified and described three key aspects of second language that are needed for effective language learning in CLIL contexts: exposure to the input, processing the input, and output.

After analyzing the data, as it is demonstrated in Tables 1 and 3, the results showed that there was not a significant difference among students' performance in the pre-test. However, there was a significant difference among the performance of the control and experimental groups in the posttest. Therefore, it could be observed that students who are taught reading through CLIL got better scores than the control group.

The main reason that the learners who were involved in a CLIL program achieved better results in terms of reading comprehension is that students who dealt with CLIL are much more exposed to reading texts because CLIL lessons are mostly based on reading resources. This agrees with Wolff (2007) who notes that this method gives much input to the learners in a comprehensive way. The underlying rationale is that input and particularly, comprehensible input has a lot of importance in CLIL sessions, especially oral and written input (Dalton-Puffer, 2008). Another reason is that CLIL lessons promote cognition and thinking processes, which means that CLIL pupils can link better concept formation, understanding and language which are in line with Coyle (2006).

The results of the study are also in line with Peeck (1993) who states the reasons that pictures and images facilitate learning, include increasing motivation, focusing attention, depth of processing, clarification of text content, dual-coding theory, distinctive encoding, decreasing interference/decay, processing support for the type of information typically extracted from a specific type of text. Therefore, based on his theory, CLIL which teaches reading through enriched texts including pictures, make reading texts more concrete and tangible for students, facilitates acquiring reading skill and accelerates learning a new subject. Therefore, teaching reading through images and pictures can: (1) facilitate, accelerate and strengthen the perception, comprehension and long retention of vocabularies and concepts of the texts, (2) facilitate reciting, paraphrasing and answering the questions, (3) activate learners' background knowledge, and (4) enhance students' motivation and interest. Moreover, following the findings of this study, CLIL is an innovative approach that deeply and positively influences the learning process regarding pedagogical aspect, i.e. the didactics of language teaching, cognitive aspects, i.e. the way the learner digests the learned material, and met-cognitive aspects, i.e. the way the learners learn how to think critically on the content.

On the other hand, the findings of this study are against Swain (1995) since his research on immersion pupils found out about the problems of grammatical development and analyzed students' learning environment, i.e. their CLIL lessons. He identified several reasons for the limited success of them: (1) The restricted input and output (Due to these restrictions certain cognitive processes are 
not possible which seem to be necessary in order to develop native-like grammar levels in the target language), (2) The limitation of acquisition opportunity, (3) The lack of certain grammatical structures in classroom discourse such as conditional and Past tenses, etc., and (4)limited output which leads to little output and lack of interaction could be observed in the classroom, (5) since a few of grammatical errors which occurred in the students' output were corrected, the learners were not pushed to more accurate language use. Therefore, Swain concluded that comprehension-based classrooms do not pose ideal environments for language learning, despite providing much comprehensible input and conditions which allow for a low affective filter, since the teachers focused solely on meaning. Furthermore, the findings of this study are against.

\section{Conclusion}

The study began with the assumption that students who are taught reading comprehension through CLIL, learn and perform better than those who are taught through intensive reading. The researcher had two classes each includes 30 students (i.e., high and low achievers). After taking the pre-test each group was divided into two groups. Therefore, there were four sub groups: two groups of high and two low achievers. Two groups of low achievers were considered as experimental groups and two groups of high achievers were considered as the control groups. After treatment and the post- test, the improvement of two high achievers in the experimental group was significant. The control groups in the high and low achievers showed less improvement in the post-test. It is suggested to implement the method other age levels. The last reason is that the researcher implemented the CLIL method among pre- intermediate learners. It is suggested to implement the method among the learners with upper and lower levels (Mearns, 2012). Lack of appropriate text books matched with CLIL method was another problem.

\section{REFERENCES}

[1] Aldaz, I. F. (2013). The use of stories in CLIL. Nafarroako Universitate Publikoa. Universidad Publica de Navarra.

[2] Coyle, D. (1999). Theory and planning for effective classrooms: Supporting Students in Content and Language Integrated Learning Contexts. Brussels: Eurydice Network.

[3] Coyle, D. (2006). Developing CLIL: From theory to practice. Barcelona: APAC Monograph 6. Barcelona: APAC.

[4] Coyle, D. (2007). Content and language integrated learning: Towards a Connected Research Agenda for CLIL Pedagogies. International Journal of Bilingual Education and Bilingualism, 10(5), 543-562.

[5] Coyle, D (2010). Content and language integrated learning. Cambridge: Cambridge University Press.

[6] Coyle, D., Hood, P., \& Marsh, D. (2010). CLIL Content and language integrated learning. United Kingdom: Cambridge University Press.

[7] Cummins, J, \& Swain, M. (1996). Bilingualism in education: Aspects of theory research and practice. London: Longman

[8] Dalton-Puffer, C. (2008). Outcomes and processes in content and language integrated learning (CLIL): current research from Europe. Retrieved 12, June, 2016 from http://www.univie.ac.at/Anglistik/Dalton /SEW07/CLIL

[9] Dalton-Puffer, C. \& Smit, U. (eds.), (2007). Empirical perspectives on CLIL Classroom discourse. Frankfurt: Peter Lang. 
[10] Divljan, S. (2012). Content and language integrated learning (CLIL) in teaching language to young learners. Faculty of Education in Jagodina. University of Kragujevac.

[11] Foresman, S. (2006). Scot Foresman science book series. Pearson Education, Inc. Printed in the United States of America.

[12] Gefall, C. (2009). Empirical and theoretical perspectives on language learning in CLIL: Delineating opportunities and limitations. Lehramtsstudium Unterrichtsfach Englisch, Unterrichtsfach Geschichte, Sozialkunde und Politische Bildung Betreuerin: Ao. Univ.-Prof. Dr. Christiane Dalton-Puffer

[13] Krashen, S. (1985). The Input hypothesis: Issues and implications. New York: Longman.

[14] Lightbown, P., \& Spada, N. M. (2006). How languages are learned (3rd ed.). Oxford, England: Oxford University Press.

[15] Marsh, D. (2002). The relevance and potential of content and language integrated learning

[16] (CLIL) for achieving MT+2 in Europe. European language Council Report.

[17] Mearns, T. L. (2012). Using CLIL to enhance pupils' experience of learning and raise attainment in German and health education: a teacher research project. The Language Learning Journal, 40 (2), 175-192.

[18] Mehisto, P. (2012). Excellence in bilingual education system: Focuses, mechanisms, and counterweights. Cambridge: Cambridge University Press.

[19] Mehisto, P., Marsh, D., \& Frigols, M. (2008). Uncovering CLIL: Content and language integrated learning in bilingual and multilingual education. Oxford: Macmillan.

[20] Merikivi, R., \& Päivi, P. (2014). Vocabulary in CLIL and in mainstream education. Journal of Language Teaching and Research, 5(3), 487-497.

[21] Munoz, C. (2014). The Association between aptitude components and language skills in young learners in M, Pawlak.and L. Aronin(Eds). Essential topic in applied linguistics and multilingualism (pp. 51-68). Heidelberg: Springer.

[22] Munoz, C. \& Naves, T. (2007). Windows on CLIL in Spain. The Hague, European Centre for Modern Languages, 160-165.

[24] Naves, T. (2010). Does content and language integrated learning and teaching have a future in our schools? Barcelona: APAC. Retrieved July 15, 2016 from www.apac.es/publications/documents/naves.doc

[25] Ortiz, C. (2014). Cámara facultat d'educació, traducciói ciències humanes universitat. Central de Catalunya (Uvic_UCC) Vic, 16th.

[26] Lee, L. (2011). Select readings: Elementary. Oxford: Oxford University Press.

[27] Peeck, J. (1993). Increasing picture effects in learning from illustrated text. Learning. Instruction, 3, 227-238.

[28] Saville, T. M. (2006). Introducing second language acquisition. Cambridge: Cambridge University Press.

[29] Solé, I. (1998). Estrategias de lectura (8ª ed.). Barcelona: Graó.

[30] Swain, M. (1995). Discovering successful second language teaching strategies and practices: from program evaluation to classroom experimentation. Journal of Multilingual and Multicultural Development, 17(2- 4), 89 -104.

[31] Swain, M., \& Lapkin, S. (1995). The Evolving Sociopolitical Context of Immersion Education in Canada: Some Implications for Program Development. International Journal of Applied Linguistics, 15(2), 169-186.

[32] Valdivia, A. (2012). The design of content and language integrated learning (CLIL) Course for the interwoven development of content, communication, cognition and culture. Facultad de Ciencias de la Educacion. Universidad de Piura. 
Bulletin de la Société Royale des Sciences de Liège, Vol. 85, 2016, p. 1642 - 1652

[33] Wolff, D. (2007). Bilingualer sachfachunterricht in EU: Versuche Ines systematischen uberblicks. Fremdsprachen Lehren \&Lernen, 36, 13-29.

[34] Zurek, O. (2012). Teaching mathematics through English Mathematics as a CLIL subject. Palacky University Olomuc. Faculty of Education. Department of English. 